\title{
Effectiveness of Cooperative Learning on English Communicative Ability of 4th Grade Students in Bhutan
}

\section{Tashi Dendup}

M.Ed., Faculty of Education, Naresuan University, Thailand, dendupt5@gmail.com

\author{
Angkana Onthanee \\ Lecturer, Faculty of Education, Naresuan University, Thailand, angkanao@nu.ac.th
}

This study examined the effectiveness of cooperative learning (CL) in enhancing the English communicative abilities (ECA) of 4 th grade students in a remote Bhutanese school in South-west Bhutan. Traditionally, teaching in Bhutan has been by the rote method where students learn the material primarily to pass tests and have limited opportunities or follow through with application of language skills in real life. Although Bhutan has been using English as the medium of instruction for more than 5 decades, most Bhutanese students are found to have a very low ECA. $\mathrm{CL}$ is an accepted strategy in other countries for teaching with the application of skills. The study involved teaching the modalities of listening, reading, writing, and speaking with CL techniques to students not familiar with the CL approach. The study was conducted with 19 grade four students at a school located in a remote and scarcely populated area which is common for all rural schools in Bhutan. Pre and post testing (one group pretest-posttest design) was administered to assess increases in skills. The study revealed that the $\mathrm{CL}$ teaching style was effective in enhancing ECA. Therefore, cooperative learning may well be an effective teaching strategy to increase ECA in Bhutan.

Keywords: cooperative learning, English communicative ability, English as a second language, rural Bhutan, traditional method

\section{INTRODUCTION}

There has been unprecedented progress in education in Bhutan beginning in the 1960's along with a national recognition of the importance of English as an essential tool of the international business community. English has become the primary language for instruction and all subjects are taught in English except the language classes in Dzongkha, the national language of Bhutan (Biddha \& Thinley, 2010). Thus, specific ECA play an indispensable role in the process of acquiring secondary and tertiary education in Bhutan because specific language skills like reading, writing, listening and

Citation: Dendup, T., \& Onthanee, A. (2020). Effectiveness of Cooperative Learning on English Communicative Ability of 4th Grade Students in Bhutan. International Journal of Instruction, 13(1), 255-266. https://doi.org/10.29333/iji.2020.13117a 
speaking provide real language opportunities as opposed to the rote teaching of English only as the study of grammar.

Despite English being the medium of instruction, most of the Bhutanese students have to retake the International English Language Testing System (IELTS) to obtain the minimum required scores (LaPrairie, 2014) and Bhutanese students are found to have low critical thinking, communication and problem-solving skills (World Bank, 2009 as cited in Rabgay, 2018). The lack of sufficient ECA is prominent especially in rural areas as indicated in the study conducted by World Bank (2009) stating that the performance of Bhutanese students in English is directly related to the student's economic background and parental literacy. To achieve increased success rates on this test, the basic foundation of English skills should be made strong from the grassroots level of primary grades since even the students at the university level lack speaking skills good enough for effective communication in academic and social situations (Biddha \& Thinley, 2010).

In most of the schools in Bhutan, the teachers have been using a traditional method of direct instruction to deliver lessons and transfer knowledge and skills. Research by LaPrairie (2014) found that the teaching and learning practices in Bhutan are heavily inclined towards the traditional method of rote learning and memorization. Rabgay (2018) mentions that, "this teaching method hardly uses innovative teaching techniques and instructional practices are not constructive" (p.266). According to Wangmo (2019), teacher-centered instruction in Bhutan has resulted in poor student English skills. Because of this, it is imperative that newer techniques and practices be applied to improve results.

One way to address this issue is for concerned authorities and stakeholders to look for ways to overhaul teaching styles by encouraging the teachers to use innovative and interactive teaching techniques other than traditional rote learning. LaPrairie (2014) suggested that teachers should learn the best teaching methods to teach English as a second language (ESL). If learners are not familiar with the second language, using that language as a medium of instruction makes learning difficult. Since teachers in Bhutan have learned ESL and are teaching students who are learning ESL then all the pedagogical approaches proven successful for teaching ESL might well be applied. Hoover, Sarris, and Hill (2015) highlight the need for the teachers to identify and make appropriate pedagogical modifications for the ESL classroom setting. Lack of proper modifications and implementation will lead to inadequate progress. Research by Piller and Skillings (2005) about English Language Teaching revealed that effective instruction for English learners should develop proficiency in the natural language through activities related to the children's everyday experiences, recitation, repetition, and practice of knowledge and skills. According to McDonell (1992), "the CL classroom is well-suited for second language learners as it enables them to communicate, collaborate, solve problems, and think critically" (Zuo, 2011, p. 987).

$\mathrm{CL}$ has the roots of constructivist learning theories and characterized by an educational paradigm shift from the teacher-centered to learner-centered teaching (Muraya \& Kimamo, 2011). Much research has been conducted to determine the effectiveness of 
CL all over the world and most of the studies have revealed that it has a positive effect irrespective of the subject and the diversity of the students. "More than 500 researchers have concluded that CL produces gains across all content areas, all grade levels, and among all types of students including special needs, high achieving, gifted, urban, rural, and all ethnic and racial groups" (Kagan, 1999, para. 2). The students in CL get mastery over the learning material by working together, helping each other and sharing of ideas (Ahmad, 2010). CL involves every student searching for the solution and performs the task which is beneficial for both the self and the other members of the group improving the productivity of content knowledge and in enhancing cognitive, social, emotional and motivational processes (Vrhovec, 2015). According to Anderson (2019), CL was designed for secondary and primary classes and states that it works in English language classrooms. CL maximizes the motivation allowing individual learners to showcase their talents enabling self-learning, building self-confidence and develops positive attitude towards other members of the group (Kirbas, 2017)

Research has been conducted across the world about how CL increases student achievement and is characterized by special activities that can foster peer interaction, which at the same time help the development of communicative language and the learning of concepts and content (Alrayah, 2018). The students who peer teach will have better retention and the recipients will enjoy the free learning from friends without fear. According to Vrhovec (2015), communication skills can be enhanced positively by applying the method of CL and its constant application of socializing activities offers our children an opportunity to communicate and acquire all those language skills. Research by Alghamdy (2019), concluded that CL improved students' English skills, oral presentation skills, self-confidence, motivation, taking of responsibility, sharing and respecting others' views, and developed good relationships with their classmates.

Even though CL is so internationally popular it is rarely practised by teachers in Bhutan. Although CL has been introduced to teachers during their pre-service training, they seldom use it after they become full-fledged teachers (Rabgay, 2018). The feedback from teachers in several studies by the ministry and experts revealed the difficulty in engaging students as one of the challenges in the conventional teaching method (Wangdi, 2016). So, the ministry, after realizing the advantages of CL, arranged for all teachers to be trained in transformative pedagogy based on Spencer Kegan's cooperative learning structures which emphasize student engagement, participation, ownership and making learning processes fun and exciting (Wangdi, 2016).

Since many world educators applaud the usefulness of CL and the Bhutanese ministry of education had provided for CL training with little evidence of it being embraced in general by the teachers of Bhutan, this study aimed to assess the effectiveness of CL in improving ECA of $4^{\text {th }}$ graders and therefore encourage Bhutanese teachers to appreciate its effectiveness in the Bhutanese schools.

\section{LITERATURE REVIEW}

\section{Cooperative Learning}

"Cooperative learning is an instructional task design, that engages students actively in achieving a lesson objective through their own efforts and the efforts of the members of 
their small learning team" (Leighton, 2011, p. 257). Johnson, Johnson, and Holubec (1994) defined Cooperative learning as "the instructional use of small groups that allow students to work together to maximize their own and each other's learning" (p.3). Any assignments in any curriculum for any age student can be done cooperatively (Johnson \& Johnson, 2010, p. 202). However, (Johnson et al., 1994) mentioned that, "simply placing the students in groups is not cooperative learning but CL is more than just small group activities" (p. 5). It is guided by five principles of CL.

\section{Principles of $\mathbf{C L}$}

Positive interdependence: One of the characteristics of the lessons taught to the $4^{\text {th }}$ grade sample in the study involved sharing and movement helping each other in doing the group task so that they progress together thus enhancing positive interdependence. It is the heart of CL as each member's effort benefits not only the individual but all other members as well and that one cannot succeed unless everyone succeeds (Johnson et al., 1994). They must depend, support and learn from each other. Johnson and Johnson (2011) interprets figuratively, "it is the group that sinks or swims together" (p. 3).

Promotive Interaction: Through various techniques of CL, the students were also given an opportunity to optimize and promote each other's success by helping, assisting, supporting, encouraging and praising each other's efforts to learn (Johnson et al., 1994). It includes orally explaining how to solve problems, discussing the concepts being learned, teaching one's knowledge to classmates, and connecting present and past learning.

Individual accountability (IA): Thirdly, the students were made responsible and accountable with their own share of contribution for the group task. The purpose of CL is to make each member a stronger individual. Students learn together so they can subsequently perform better as individuals. IA identifies students who need more assistance, support, and encouragement in completing the task (Johnson et al., 1994). Students cannot hitchhike on the work of others.

Interpersonal Skills: CL requires students to learn both academic subject matter and interpersonal skills required to function as a part of a team (teamwork) to complete the task successfully and collaboratively. This makes CL inherently more complex than competitive or individualistic learning (Johnson et al., 1994). Some of the social skills are praising each other, listening as a sign of interest and respect, exchange of ideas, keeping each other on task and making connections to prior knowledge (World Education, 2009).

Group Processing: Students need to regularly reflect and discuss on how well they are achieving their goals, to what extent they have achieved a goal, and maintaining effective working relationships (World Education, 2009). The students can orally discuss the ways to solve problems, sharing of one's ideas, connecting present and past learning, discuss each other's helpful and awkward behaviours and decide the behaviours to be continued and changed.

\section{Techniques of $\mathbf{C L}$}

During the study, four techniques of CL were employed based on the relevancy with subject, content, context, kind of activity and the objectives of the lesson. One activity 
was when students worked in a 'homegroup' and 'expert group' called Jigsaw II (Suroto, 2017). Students with the same material from different homegroups would go to the expert group to become an expert about their common material. Experts then go back to the homegroup to teach other members of the group followed by a quiz or presentation. Sometimes students were engaged in various ways for the single activity; thinking, paring and sharing (Arends, 2004) called the activity Think-Pair-Share. For this, the teacher poses a question and the students think individually, share in pairs and finally selective students share the key ideas to the whole class. The third technique, Student Team Achievement Divisions (STAD) was used when students had to master the lesson presented by the teacher in groups which were then followed by individual quizzes. The score is then added into the team score based on the degree of improvement and the team meeting certain criteria may earn rewards (Slavin, 1995). Fourthly, the Numbered Heads Together was another technique developed by Kagan to check the understanding of the content taught by asking questions in different ways which keep the student alert. According to (Arends, 2004), it involves numbering, questioning, putting heads together and answering.

\section{Theoretical Underpinning: Social Constructivism}

The main philosophy behind CL is social constructivism as developed by Lev Semyonovich Vygotsky (1896-1934). Vygotsky stated that the development of individuals, including their thoughts, languages, and reasoning processes, is a result of social interactions sharing the knowledge of a given culture. Vygotsky's study about the growth of children from their environment and interaction with others revealed that what happens in the social environment helps children learn, develop, and grow (Li \& Lam, 2002). Vygotsky further relates it to the zone of proximal development (ZPD), which is defined as "the distance between the actual developmental level as determined by independent problem solving and the level of potential development as determined through problem solving under adult guidance or in collaboration with more capable peers" (Vygotsky, 1978 as cited in Tran, 2013, p. 106). This implies that the tasks which are too difficult for children to master alone can be learned with guidance and assistance from adults, more-skilled children, or more knowledgeable others. Vygotsky explained that the upper limit in the ZPD cannot become fruitful without social interactive support from peers and teachers. This activity, called scaffolding, refers to the temporary assistance given to students in completing tasks that they cannot complete by themselves. It is intended to increase the learner's autonomy as Vygotsky said, "what a child can do with support today, she or he can do alone tomorrow" (Gibbons, 2002, p. 16). In Vygotsky's social constructivism, social interactions are believed to be the best ways of exchanging ideas and receiving information leading to better understanding and knowledge.

\section{METHOD}

This research was based on Experimental design (one group pretest-posttest design) (Ary, Jacobs, Irvine, \& Walker, 2014) to examine the effectiveness of CL in enhancing ECA. The data were collected by conducting ECA pre and post-tests. 
The participants of the study were 19 students, aged between 10-12 years from fourthgrade studying at the Zinchella Primary School in a remote village within the Dagana, Bhutan. 12 were girls and 7 were boys. All were average performers in general without any over or underachieving, or, special needs students. The sample for the study is small because of the nature of the remote and unpopulated community common throughout the district. Most of the students are from low-economic backgrounds and their parents are illiterate farmers. The sample was chosen purposively as the researcher had some teaching experience with the same grade in the traditional method and it would be less challenging to handle the differences with the new method.

The study lasted for 5 weeks including one and a half hours per day teaching of the syllabus and the testing time. The unit, "It is Time to Be a Hero" was chosen from the regular English curriculum of grade four of Bhutan and had six sub-topics of mixed genres. The students were divided into small groups based on the heterogeneous grouping considering past achievement, gender, age and diligence level. Table 1 shows the details of all the subtopics with the CL techniques used.

Table 1

Lesson Topics and CL Techniques

\begin{tabular}{clll}
\hline \multicolumn{2}{l}{ Topics } & Genre & Techniques \\
\hline 1. & Summit Success & Informational text & Think-pair-share \\
2. & Emil and the Detectives & Short story & Jigsaw, STAD \\
3. & Riding the Rapids & Informational text & Jigsaw \\
4. & White Water & Poem & Think-pair-share \\
5. & Stubborn Marry Shadd & Informational text & Jigsaw \\
6. & Underground Road to Freedom & poem & Numbered heads together \\
\hline
\end{tabular}

\section{Research Instruments}

ECA tests: ECA pre and post tests were administered about each of the focus skills of listening, reading, writing and speaking. Pre-tests were given in week one and the posttests in week five to compare the pre-test and post-test scores of the ECA after using CL activities that would determine the effectiveness of the CL. The test questions were evaluated by five experts to ascertain the content validity and reliability of the test questions. For listening, the students listened to the audio conversation and answered 5 multiple choice questions (MCQs), 5 fill in the blanks and 5 short answer questions for the duration of 30 minutes. For reading, a passage was given to read and comprehend and to answer $5 \mathrm{MCQs}, 5$ fill in the blanks and 5 short answer questions for the duration of 30 minutes. For writing, students wrote an essay on one of the topics from three choices in 30 minutes. It was assessed using the rubrics considering the components like ideas, organization, expressions, conventions and legibility. For speaking ability, students were asked to deliver a short extemporaneous speech for 2-3 minutes to assess speaking ability based on the rubrics: introduction, content relevancy, language, delivery and conclusion.

Lesson plans: Lesson plans were created to provide skill building in listening, reading, writing and speaking characterized by CL methodology. The teaching was solely guided by lesson plans designed by incorporating the techniques of CL using essential components like information, lesson objectives, introduction, development and activities, monitoring, follow-up, lesson closure and evaluation. The lesson plans were 
checked by 5 experts and verified for quality using the Likert scale. The expert panel was comprised of two lecturers from Thailand, and one lecturer at the teaching college in Bhutan and two senior English teachers teaching in primary schools of Bhutan.

The lessons for listening were planned to focus on various activities like listening to presentations, peer sharing, teacher's instructions, explanation and summaries followed by assessments. Reading was emphasized on both the oral reading (pronunciation, intonation, gestures, fluency etc.) and the reading comprehension of understanding of the text through the activities of referring to a dictionary and presentations and responding to various questions. The writing was mainly focussed on writing basic sentences using the new vocabularies and writing their own piece similar to the text they had studied in the lesson. Speaking was intended to increase the ability of the students to communicate with others during the discussions, presentations, answering the oral questions and the speeches.

\section{Data analysis}

The data was analyzed based on a quantitative design. The Scores from the pre-test and post-tests were analyzed with the paired sample t-test and calculation of mean and standard deviation from the Statistical Package for Social sciences (SPSS) software.

\section{FINDINGS}

To study the effectiveness of CL in enhancing the ECA as determined by the scores of the pre-test and post-test, Table 2 presents the mean and standard deviation separately for each of the abilities in the pre-test and the post-tests.

Table 2

Paired Sample Test for English Communicative Ability Test Scores in Pre-and Post-Test for Each Ability

\begin{tabular}{llllllll}
\hline Variables & & $\mathrm{N}$ & $\overline{\mathrm{X}}$ & $\mathrm{SD}$ & $\mathrm{MD}$ & $\mathrm{t}$ & Sig \\
\hline Listening & Pre-test & 19 & 7.63 & 2.27 & 6.76 & 14.51 & 0.000 \\
& Post-test & 19 & 14.37 & 2.50 & & & \\
\cline { 2 - 8 } Reading & Pre-test & 19 & 7.84 & 2.01 & 4.73 & 10.99 & 0.000 \\
& Post-test & 19 & 12.57 & 2.06 & & & \\
\cline { 2 - 8 } Writing & Pre-test & 19 & 9.79 & 1.78 & 5.00 & 12.36 & 0.000 \\
& Post-test & 19 & 14.79 & 2.53 & & & \\
\cline { 2 - 8 } Speaking & Pre-test & 19 & 9.79 & 2.12 & 4.63 & 0.000 \\
& Post-test & 19 & 14.42 & 2.89 & & & \\
\hline
\end{tabular}

Note: $\overline{\mathrm{x}}$ (mean), SD (standard deviation), Significance at the $\mathrm{p}<0.001$

Table 2 above shows the ECA scores of the pre-tests and post-tests. The mean score of each of the four abilities, listening, reading, writing and speaking was calculated separately using the paired sample t-test statistical procedures. As the table indicates, the overall students' mean scores for the four abilities had nearly doubled in the post-test. The mean score for listening increased from 7.63 to 14.37 , reading from 7.84 to 12.57 , writing from 9.79 to 14.79 and the speaking from 9.79 to 14.42 .

As indicated by Table 2 above, the mean differences of all the four skills were statistically significant in post-test at $(\mathrm{p}<0.001)$. The mean score difference between the pre-test and post-test was 6.74 in listening, 4.73 in reading, 5.00 in writing and 4.63 in speaking. 
Table 3

Paired Samples Test for Mean Difference in English Communicative Ability Test Scores in Overall Pre-and Post-Test

\begin{tabular}{lllllll}
\hline Test & $\bar{X}$ & SD & MD & t & df & Sig \\
\hline Pretest & 35.02 & 6.62 & 21.10 & 22.10 & 18 & 0.000 \\
Posttest & 56.15 & 7.34 & & & & \\
\hline
\end{tabular}

Note: Significance at the $\mathrm{p}<0.001$

The table indicates the mean difference in the overall or total score of the four skills and the mean difference indicated is 21.11 with a standard deviation of 4.16 . This results in a $\mathrm{t}$-value of $\mathrm{t}=22.10$ significant at the $\mathrm{p}<0.001$. The $95 \%$ confidence interval for the average difference of the mean is (19.10-23.11). Therefore, the ECA of the students is significantly better in the post-test than the pretest indicating the positive effects of CL activities in enhancing the ECA of the students.

Each pre and post-test for listening, reading, writing and speaking had a possible perfect score of 20. After the pre and post tests were evaluated a total score for each student was determined for the pre and then post tests and these totals were divided by 4 to provide a number based on a spread of $0-20$ providing an achievement categorization from fail to excellent as outlined in Table 4 below.

Table 4

Students' Score Range in Pre-and Post-Test in Percentage

\begin{tabular}{|c|c|c|c|c|c|c|c|c|c|c|c|c|}
\hline \multirow[t]{3}{*}{ Test } & \multicolumn{2}{|c|}{ Excellent } & \multicolumn{2}{|c|}{ Very good } & \multicolumn{2}{|c|}{ Good } & \multicolumn{2}{|c|}{ Satisfactory } & \multicolumn{2}{|c|}{ Acceptable } & \multicolumn{2}{|l|}{ Fail } \\
\hline & $18-$ & & $16-$ & & 14- & & $12-1$ & & $8-1$ & & $0-7$. & \\
\hline & Std & $\%$ & Std & $\%$ & Std & $\%$ & Std & $\%$ & Std & $\%$ & Std & $\%$ \\
\hline Pretest & 0 & 0 & 0 & 0 & 0 & 0 & 0 & 0 & 9 & 47.3 & 10 & 52.7 \\
\hline Posttest & 0 & 0 & 1 & 5.3 & 7 & 36.8 & 6 & 31.6 & 5 & 26.3 & 0 & 0 \\
\hline
\end{tabular}

Note: Std (number of students), \% (percentage)

The above table illustrates that, during the pre-test, $52.7 \%$ (10 students) of the students failed and only $47.3 \%$ (9 students) of the students passed. The students who passed were just in 'acceptable' range and none of the students scored in other ranges like satisfactory, good, very good and excellent. Whereas during the post-test, all the students passed with $26.3 \%$ (5 students) of the students under 'acceptable' range, $31.6 \%$ (six students) in 'satisfactory', 36.8\% (7 students) in 'good' and 5.3\% (1 student) in 'very good' although none could score in the excellent range.

\section{DISCUSSION}

Even in writing, there was a significant improvement over a short of time period which is unusual according to some like (J. Shanahan, personal communication, January 17, 2019), who stated that because all writing is composing thoughts and ideas in sentences and paragraphs, it is developmental and takes time to develop. He added, "improvement in compositional writing takes time to show a difference in a pre and post-test scheme. In New York state in the USA, students writing ability is assessed only every few years as it is recognized that language study, growth and development of the child, and the mind's ability to compose thoughts in logical and expressive ways develops over time." However, research on ESL writing by Wangmo (2019) using CL resulted in increased writing ability with positive feedback from the students. Vrhovec (2015) found that use 
of CL enhances both verbal communication and writing skills which are the result of providing the students with a relaxed learning environment and frequent application. Moreover, Hengki, Jabu, \& Salija (2017) also found out that using CL for teaching speaking skill in academic language function was more effective after the intervention.

During the study, the researcher observed initially that the students were reluctant to cope with the CL styles like, not willing to open-up and participate as per the CL activity even when the teacher selected them to answer. Perhaps the reason for this is that the students had been trained to be passive without any response as a result of traditional method teaching, where they just learn to say, 'Yes Sir' and 'No Sir', whereby the culture of raising doubts and sharing their views was never instilled. Early in the study, it appeared they were afraid of the embarrassment from friend's mockery and teachers scolding in case of a wrong answer. The teacher even had to encourage the students to respond and wait for the student to stand and share. Gradually, some of the high achieving and confident students started to open-up, encouraged by the situation and felt comfortable over a few days and then started encouraging others for common goals. Towards the end, it was observed that gradually even the low achievers and the students with low self-esteem raised their hands to answer even when they had the wrong answer or only sometimes the correct answer. It is because CL enables learners' active participation in learning and accomplish learning tasks in a constructive way through mutual encouragement and motivation (Fan, 2018). Similarly, Rabgay (2018) also found that older students demonstrated a positive attitude when taught using CL indicated by an increased level of interest, satisfaction and understanding.

As the study progressed, students interacted freely with their friends without any hesitation and with reduced anxiety which is similar to the findings of (Çelik, Aytın, \& Bayram, 2013). Students also demonstrated an increased ability to discuss tasks with peers improving the use of communication skills with a variety of skill level in students, which is similar to the findings of Singay (2018), who found out extensive peer interaction improves the quality of oral communication as a result of frequent use of tasks related to oral language functions. According to Alrayah (2018), cooperative learning involves special activities that foster peer interaction and help the development of communicative language and learning of concepts and content. The use of the dictionary in the CL task for meaning and sharing improved their vocabulary and comprehension which is also important for oral communication of listening and speaking. Similarly, a study by Singay (2018) indicated increased interest by the experimental group to participate in oral communication as a result of CL intervention which is further strengthened by Kagan (1994)'s statement, "CL was actually a practice that can put the communicative approach into action" (Singay, 2018, p. 306). As embraced by the principles of interdependence (Anderson, 2019), students were found very active in helping and encouraging each other in the group for common goals because after all it's all the members that will swim or sink together and without positive interdependence, students may or may not cooperate.

Gagné and Parks (2013) stated scaffolding in CL is the tool to encourage the interaction amongst the students which develops the communicative ability of the students. Research about CL by (Alghamdi, 2014) observed a significant difference in making 
basic statements in the discussion, responding to others' requests for basic information with brief statements, explaining with examples, positive interruption, and supporting others in the group. The students in the CL classes learn to negotiate with others for common consensus and refine their own language skills in an attempt to provide comprehensible input to their group members (Careen, 1997).

With CL, the students learn in small mixed ability groups through active engaging activities relating to the children's everyday experiences and practicing of knowledge and skills. Assigning of different roles for the different tasks provides the students with an equal opportunity for the students to interact, discuss, give comments, explain to each other, experience joint preparation and assess expansively enhancing the ECA of the students. Some other reasons are active involvement of all students, integration of individual and group, giving equal opportunities for all, regular follow-ups and motivating factors of the conducive classroom environment resulting from the CL strategies. Perhaps one factor accounting for the increase of scores in post-tests across all modalities tested could be due to the novelty of the CL experience and the joy of having fun in the classroom beyond the rigors of the rote method.

\section{CONCLUSION}

The results from this study revealed that post-test scores in all four modalities of listening, reading, writing and speaking indicated increased skills after the use of CL as the posttest scores were significantly higher than the pretest scores. Moreover, as per the observation made during study by the researcher, students demonstrated an increased interest and ability to use communication skills during CL activities. Therefore, it is concluded that the CL activity can be used as an effective teaching approach to enhance the ECA of the students in the ESL context and particularly in the Bhutanese school context.

\section{RECOMMENDATIONS}

The teachers of Bhutan should be well trained in the use of CL strategies through innovative programs like providing CL experienced teachers to perform demonstration classes for a short unit to show the teachers both the method and the ways the students respond. After the training, the concerned authorities need to monitor its application periodically by checking the lesson plans and observing the classes and taking note of achievement increases. Moreover, similar studies need to be conducted with larger samples across more age groups, grade levels and wholes districts in Bhutan and compare those results with those of studies in other countries.

\section{REFERENCES}

Ahmad, F. (2010). Effect of cooperative learning on students' achievement at elementary level. International Journal of Learning, 17(3), 127-141. http://doi:10.18848/14479494/CGP/v17i03/46928.

Alghamdi, R. (2014). EFL learners' verbal interaction during cooperative learning and traditional learning (small group). Journal of Language Teaching \& Research, 5(1), 21-27. http://doi:10.4304/jltr.5.1.21-27. 
Alghamdy, R. Z. (2019). EFL learners' reflections on cooperative learning: Issues of implementation. Theory and Practice in Language Studies, 9(3), 271-277. http://dx.doi.org/10.17507/tpls.0903.03.

Alrayah, H. (2018). The effectiveness of cooperative learning activities in enhancing EFL learners' fluency. English Language Teaching, 11(4), 21-31. http://doi.org/10.5539/elt.v11n4p21.

Anderson, J. (2019). Cooperative learning: Principles and practice. English Teaching Professional, 121, 4-6.

Arends, R. I. (2004). Learning to teach. Boston: McGraw-Hill.

Ary, D., Jacobs, L. C., Irvine, C. K. S., \& Walker, D. (2014). Introduction to research in education. Cengage Learning.

Biddha, S., \& Thinley, D. (2010). Building students' oral fluency: Perspectives on the use of spoken English in Bhutanese classrooms. RABSEL the CERD Edu. J, XIV, 11-34.

Careen, K. (1997). A study of the effect of cooperative learning activities on the aural comprehension and oral proficiency of grade 6 core French students (Unpublished master thesis). Memorial University of Newfoundland, Canada.

Çelik, S., Aytın, K., \& Bayram, E. (2013). Implementing cooperative learning in the language classroom: opinions of Turkish teachers of English. Procedia-Social and Behavioral Sciences, 70, 1852-1859. http://doi: 10.1016/j.sbspro.2013.01.263.

Fan, X. (2018). Research on oral English flipped classroom project-based teaching model based on cooperative learning in China. Edu. Sci.: Theo.\& Pr., 18(5), 1988-1998.

Gagné, N., \& Parks, S. (2013). Cooperative learning tasks in a Grade 6 intensive ESL class: Role of scaffolding. Language Teaching Research, 17(2), 188-209. http://doi: $10.1177 / 1362168812460818$.

Gibbons, P. (2002). Scaffolding language, scaffolding learning: Portsmouth, NH: Heinemann.

Hengki, H., Jabu, B., \& Salija, K. (2017). The effectiveness of cooperative learning strategy through English village for teaching speaking skill. Journal of Language Teaching and Research, 8(2), 306-312. http://dx.doi.org/10.17507/jltr.0802.12.

Hoover, J. J., Sarris, J. S., \& Hill, R. (2015). Increasing usage of ESL instructional practices in a rural county elementary school. The Rural Educator, 36(3). Retrieved from http://epubs.library.msstate.edu/index.php/ruraleducator/article/view/300.

Johnson, D. W., \& Johnson, R. T. (2010). Cooperative learning and conflict resolution: Essential 21st century skills. In J. A. Bellanca, \& R. S. Brandt (Eds.), 21st century skills: Rethinking how students learn (pp. 201-219). Bloomington, IN: Solution Tree.

Johnson, D. W., \& Johnson, R. T. (2011). Cooperative learning. In D. J. Christie (Ed.), The encyclopedia of peace psychology (pp.?-?). Hoboken, NJ: Wiley-Blackwell.

Johnson, D. W., Johnson, R. T., \& Holubec, E. J. (1994). The new circles of learning: Cooperation in the classroom and school. Alexandria, VA: ASCD.

Kagan, S. (1999). Cooperative learning: Seventeen pros and seventeen cons plus ten tips for success. Kagan Online Magazine. Retrieved from 
https://www.kaganonline.com/free_articles/dr_spencer_kagan/259/Cooperative-LearningSeventeen-Pros-and-Seventeen-Cons-Plus-Ten-Tips-for-Success.

Kirbas, A. (2017). Effects of cooperative learning method on the development of listening comprehension and listening skills. Int. J. of Lang. Edu. \& Teac., 5(1), 1-17.

LaPrairie, M. (2014). A case study of English-medium education in Bhutan (Unpublished doctoral dissertation). University of London, UK.

Leighton, M. S. (2011). Classroom teaching skills. Australia: Wadsworth.

Li, M. P., \& Lam, B. H. (2002). Cooperative learning. Hong Kong: The Hong Kong Institute of Education.

Muraya, D. N., \& Kimamo, G. (2011). Effects of cooperative learning approach on biology mean achievement scores of secondary school students in Machakos District, Kenya. Educational Research and Reviews, 6(12), 726-745.

Piller, B., \& Skillings, M. J. (2005). English language teaching strategies used by primary teachers in one New Delhi, India school. Tesl-Ej, 9(3), 1-23.

Rabgay, T. (2018). The effect of using cooperative learning method on tenth grade students' learning achievement and attitude towards biology. International Journal of Instruction, 11(2), 265-280. http://doi.org/10.12973/iji.2018.11218a.

Singay. (2018). The effects of modified Kagan cooperative learning model on English oral communication ability of Bhutanese students. Paper presented at the 1 st International Conference on English Studies: Innovation in English Language Teaching and Learning, Krabi.

Slavin, R. E. (1995). Cooperative learning: Theory, research, and practice. Boston: Allyn and Bacon.

Suroto, M. (2017). The effectiveness of Jigsaw II model in improving students' understanding of citizenship education. Paper presented at the 5th SEA-DR (South East Asia Development Research) International Conference, Indonesia.

Tran, V. D. (2013). Theoretical perspectives underlying the application of cooperative learning in classrooms. Int. J. of High. Edu., 2(4), 101-115. doi: 10.5430/ijhe.v2n4p101.

Vrhovec, A. R. (2015). Forms of cooperative learning in language teaching in Slovenian language classes at the primary school level. CEPS Journal, 5(3), 129-155.

Wangdi, T. (2016, July 7). Teachers introduced to transformative pedagogy. Kuensel. Retrieved from http://www.kuenselonline.com/teachers-introduced-to-transformative-pedagogy/.

Wangmo, P. (2019). Integrating cooperative language learning into ESL process writing. Paper presented at the 5th National \& International Conference on Curriculum \& Instruction "Differentiated Curriculum and Instruction in the 21 st century", Thailand.

World Bank. (2009). Findings from the Bhutan learning quality survey. South Asia human development sector series; No. 21. Washington, DC.

World Education. (2009). Cooperative learning: Theory \& practice (a new guide for the teachers). Cambodia: World Education

Zuo, W. (2011). The effects of cooperative learning on improving college students' reading comprehension. Theory and Practice in Language Studies, 1(8), 986-989. doi: 10.4304/tpls.1.8.986-989. 